\title{
Central corticotropin releasing factor and social stress
}

\author{
Tobias Backström ${ }^{1 *}$ and Svante Winberg ${ }^{2}$ \\ ${ }^{1}$ Department of Wildlife, Fish, and Environmental Studies, Swedish University of Agricultural Sciences, Umeå, Sweden \\ 2 Department of Neuroscience, Uppsala University, Uppsala, Sweden
}

\section{Edited by:}

James A. Carr, Texas Tech

University, USA

Reviewed by:

Cynthia L. Bethea, Oregon Health

and Science University, USA

Rafael Vazquez-Martinez, University

of Cordoba, Spain

\section{*Correspondence:}

Tobias Backström, Department of Wildlife, Fish, and Environmental Studies, Swedish University of Agricultural Sciences,

Skogmarksgränd, SE-901 83 Umeå, Sweden

e-mail: tobias.backstrom@slu.se
Social interactions are a main source of stress in vertebrates. Social stressors, as well as other stressors, activate the hypothalamic-pituitary-adrenal (HPA) axis resulting in glucocorticoid release. One of the main components of the HPA axis is corticotropin releasing factor (CRF). The neuropeptide CRF is part of a peptide family including CRF, urocortin $1-3$, urotensin $1-3$, and sauvagine. The actions of the CRF family are mediated by at least two different receptors with different anatomical distribution and affinities for the peptides. The CRF peptides affect several behavioral and physiological responses to stress including aggression, feeding, and locomotor activity. This review will summarize recent research in vertebrates concerning how social stress interacts with components of the CRF system. Consideration will be taken to the different models used for social stress ranging from social isolation, dyadic interactions, to group dominance hierarchies. Further, the temporal effect of social stressor from acute, intermittent, to chronic will be considered. Finally, strains selected for specific behavior or physiology linked to social stress will also be discussed.

Keywords: corticotropin releasing factor (CRF), CRF-receptors, dominance hierarchies, hypothalamic-pituitaryadrenal axis, social defeat, social isolation, social stress

\section{INTRODUCTION}

The stress response elicited by social stressors does not differ from the response to other challenges. A stressor, which can be a real or perceived threat, causes a physiological response aimed at counteracting a homeostatic disruption. The immediate effect of the stress response is to prepare the animal for a quick and energetic reaction, often referred to as "the fight-or-flight response" (Cannon, 1915). "The fight-or-flight response" involves many different adaptations mainly by increasing energy availability and inhibiting processes not necessary for the immediate survival (Johnson et al., 1992; Carrasco and Van De Kar, 2003). The primary physiological stress response is mediated by the sympathetic nervous system and hypothalamic-pituitary-adrenal (HPA) axis in mammals (see Figure 1) and the hypothalamicpituitary-interrenal (HPI) axis in teleost fish (Wendelaar Bonga, 1997; Carrasco and Van De Kar, 2003). During a stress response, the hypothalamus is activated and releases corticotropin releasing factor (CRF; also known as corticotropin releasing hormone, $\mathrm{CRH}$ ), which stimulates the release of adrenocorticotropic hormone (ACTH) from the pituitary gland. ACTH induces glucocorticoid synthesis and release from the adrenal/interrenal tissue into the blood. The HPA/HPI axis is self-regulated by an array of feedback loops (Carrasco and Van De Kar, 2003).

One of the main mediators of the stress response is CRF and here we will briefly detail the distribution and main effectors of the CRF system [for a more detailed description, see review by Ronan and Summers (2011)]. CRF was initially discovered in 1955 when factors in the hypothalamus were found to induce ACTH release from the pituitary gland (Guillemin and Rosenberg, 1955; Saffran and Schally, 1955). In 1981, CRF was characterized as a neuropeptide of 41 amino acids (Vale et al., 1981) inducing ACTH release from the pituitary gland (Lederis et al., 1985). Cells synthesizing CRF are primarily found in the hypothalamus, more precisely in the parvocellular neurons of the paraventricular nucleus (PVN) in mammals (Bloom et al., 1982; Pelletier et al., 1983; Swanson et al., 1983; Raadsheer et al., 1993). CRF is also found in other brain areas including the magnocellular cells of the PVN and supraoptic nucleus (Paull and Gibbs, 1983; Delville et al., 1992; Luo et al., 1994). The CRF system seems to be well conserved since CRF synthesizing cells are found in the parvocellular neurons in the preoptic area (POA) in teleost fish (Matz and Hofeldt, 1999; Pepels et al., 2002), the teleostean POA being homologues to the mammalian PVN. A recent study suggests that CRF is also present in other areas in the teleost brain, outside the POA such as the dorsal telencephalon and suprachiasmatic nucleus (Alderman and Bernier, 2007).

The effects of CRF are mediated by at least two different receptor types, namely corticotropin releasing factor receptor 1 (CRF-R1) and corticotropin releasing factor receptor 2 (CRF-R2), and these appear to be present in both mammals (Chang et al., 1993; Chen et al., 1993; Perrin et al., 1993, 1995; Vita et al., 1993; Kishimoto et al., 1995; Lovenberg et al., 1995; Stenzel et al., 1995) and teleost fish (Arai et al., 2001; Pohl et al., 2001). The CRF-R1 have been reported to mediate the activation of the HPA/HPI axis (Timpl et al., 1998; Bale et al., 2002b; Huising et al., 2004) and to induce anxiety-like behavior (Britton et al., 1986; Heinrichs et al., 1997; Bale et al., 2002b), whereas the CRF-R2 have been reported to affect several other behavioral and physiological responses to stress (Liebsch et al., 1999; Coste et al., 2000; Bale et al., 2002b), and also to be involved in anxiety control (Bale et al., 2000, 2002a). In addition to the receptors, there is a CRF binding protein (CRF-BP), which has been reported in mammals (Potter et al., 1991; Cortright et al., 1995; Behan et al., 1996) and the teleost Mozambique tilapia (Tilapia mossambicus) (Seasholtz 


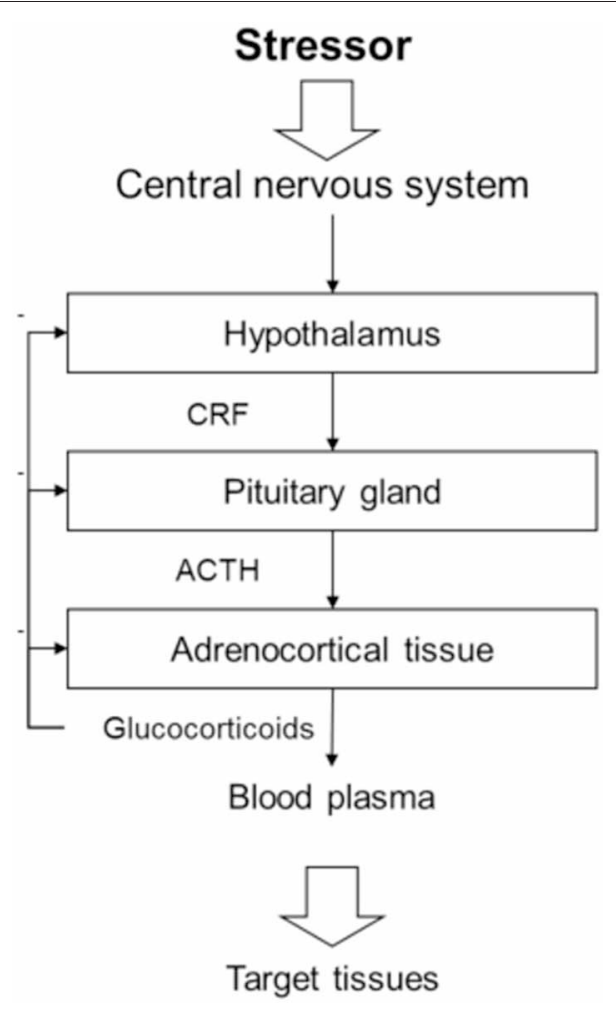

FIGURE 1 | Schematic drawing of the hypothalamic pituitary adrenocortical axis. The primary physiological stress response is partly mediated by the hypothalamic-pituitary-adrenocortical (HPA) axis in mammals. A stressor activates the central nervous system and the hypothalamus then releases corticotropin releasing factor (CRF) unto the pituitary gland. The pituitary gland will in its turn release adrenocorticotropic hormone (ACTH), which induces glucocorticoid synthesis and release from the adrenal tissue into the blood. The glucocorticoids will then affect target tissues throughout the body mainly to increase energy availability and inhibit processes not necessary for the immediate survival. Each step of the HPA axis is self-regulated by an array of feedback loops.

et al., 2002). The CRF-BP has been suggested to bind CRF with high affinity and thereby decrease CRF effects (Potter et al., 1991; Woods et al., 1994; Cortright et al., 1995).

Several neuropeptides closely related to CRF have been identified including urocortin-1, urocortin-2, and urocortin-3 in mammals (Vaughan et al., 1995; Lewis et al., 2001; Reyes et al., 2001), sauvagine in anurans (Montecucchi et al., 1979), and urotensinI (UI) in teleost fish (Lederis et al., 1982; Ishida et al., 1986; Bernier et al., 1999). The CRF-R1 binds both CRF and urocortin 1 with similar affinity whereas the CRF-R2 has a higher affinity for urocortin-1 (Vaughan et al., 1995; Donaldson et al., 1996; Ozawa et al., 1998). Urocortin-2, urocortin-3, UI, and sauvagine are mainly bound by CRF-R2 (Hauger et al., 2003). Thus, CRF$\mathrm{R} 1$ main ligands are CRF and urocortin-1, whereas CRF-R2 main ligands are urocortin-2, urocortin-3, UI, and sauvagine.

Several behaviors in mammals are affected by CRF, and CRF has been reported to increase locomotor activity, elevate anxietylike responses, and reduce feeding in vertebrates [reviewed by Heinrichs and Koob (2004) and Lowry and Moore (2006)].
Further, the CRF system is an important mediator of several behavioral stress responses [see reviews by Bale and Vale (2004), Heinrichs and Koob (2004), and Lowry and Moore (2006)]. These and several other excellent reviews describe how CRF, behavior, and physiology are interacting. However, the specifics of how social stressors and the CRF system interact have not been reviewed. Therefore, the focus of this review is on how social stressors and CRF are interacting in modulating behavior and physiology.

\section{SOCIAL STRESSORS}

Social systems and social stressors differ between species (Blanchard et al., 2001), but generally social animals form dominance-based social hierarchies. In these hierarchies, each individual has a social rank position. For example, dominance hierarchies can be linear, which means that the alpha individual, having the highest rank, dominates all other group members, whereas the beta individual being subordinate to the alpha individual dominates the rest of the group members, and so on until the omega individual, which has the lowest rank and is subordinate to all group members (Huntingford and Turner, 1987). Dominance hierarchies are often formed by agonistic interactions. These agonistic interactions are performed by two or more individuals competing for the higher social position. Initially, a phase of mutual displays and threats escalates into a phase of overt aggressive behavior including violent attacks (Huntingford and Turner, 1987). The overt aggressive behavior continues until inter-relational rank is firmly established and the subordinate individuals signal defeat and retreat. However, even after the hierarchy is established subordinate animals are subjected to social stress and show signs of chronic stress (Greenberg et al., 1984; Sapolsky, 1990; Winberg et al., 1991; Blanchard et al., 1993), especially in captivity or other situations where escape is not possible. Experimentally, the effect of social stress is often studied using dyads and thus creating one dominant and one subordinate individual. Similar pairing is also used for the resident-intruder test, where the resident typically is an experienced and aggressive fighter and thus predestined to become dominant. Intruders from these pairings are suffering social defeat, which is another common social stress model.

Social isolation can be stressful as well in several vertebrates, usually depending on social organization. In several species, either isolation or grouping would be stressful and some gender differences could also be apparent (Blanchard et al., 2001). Rodent models are often used for both social isolation and dominance hierarchies, whereas teleost fish has mainly been used in dominance hierarchical studies such as dyadic interactions. Several experiments have shown that the CRF system is important in mediating effects of social stress on aggression and anxietylike behaviors. Early studies were mainly done using exogenous administration of CRF and have continued with specific antagonist as well as site-specific administration. Further studies have been using the expression of CRF mRNA, as well as the expression of other genes related to the CRF system, to monitor the effects of acute and social stressors. Recent studies have also been using genetic engineering and thus creating deficient or knockout strains for elucidating the effects of various components of 
the CRF system. In the following sections, these studies will be reviewed.

\section{ACUTE EFFECTS OF EXOGENOUS CRF}

Aggressive behavior is crucial for establishing dominance, upholding territories, and protecting offspring. Several studies using exogenous CRF have reported modulating effects on various types of aggressive behavior in various vertebrates. However, the function of the CRF system in the control of aggressive behavior is not consistent across species. It seems that it can both induce and reduce aggression. For instance, in male mice intracerebroventricular (icv) injection of CRF as well as sauvagine reduces aggression (Mele et al., 1987). Similarly, in female mice icv injections of either CRF, urocortin-1, or urocortin-3 inhibit maternal aggression (Gammie et al., 2004; D'anna et al., 2005). Further, these responses seems to be mediated by CRF-R1, since the specific CRF-R1 antagonist antalarmin injected into the amygdala reduces defensive posture in socially defeated mice (Robison et al., 2004). In contrast, in male rats injections of CRF into the amygdala can increase aggression (Elkabir et al., 1990). Further, icv injections of the CRF non-selective antagonist $\alpha$-helical $\mathrm{CRH}_{1-41}$ decrease aggressive behavior in male rats (Aloisi et al., 1999). Similarly, the CRF-R1 antagonist SSR125543A delayed the latency to attack intruders in Syrian hamsters (Mesocricetus auratus) (Farrokhi et al., 2004). It also seems as if CRF-R antagonists reduce the behavioral effects of aggression and defeat as a social stressor. For instance, the CRF-R1 antagonist NBI-30775 increased time in defensive posture and latency to submission, and reduced the defeat stress induced immobility in rats (Wood et al., 2012). Further, the CRF non-selective antagonist d-Phe $\mathrm{CRF}_{(12-41)}$ injected into the dorsal raphe nucleus of Syrian hamster reduced both the acquisition and expression of conditioned defeat as seen by reduced submissive and defensive behavior, whereas the CRF-R2 specific antagonist anti-Svg-30 only reduced the expression of conditioned defeat (Cooper and Huhman, 2007). In a follow-up experiment, it was found that an injection of a non-selective CRF antagonist into the lateral ventricle reduced submissive and defensive behavior, and similarly a selective CRF-R2 antagonist also reduced submissive and defensive behavior, but a CRF-R1 antagonist had no effect on these behaviors (Cooper and Huhman, 2010). Thus, there is evidence for the involvement of both CRF-R1 and CRF-R2 in modulation of aggressive behavior. However, since CRF by itself elicits divergent responses in aggressive behavior, species-specific patterns could be present.

Interestingly, this ambiguity concerning the effect of CRF on aggression can be seen in a single species of teleost fish. In rainbow trout (Onchorhynchus mykiss), two studies using exogenous CRF have reached two different conclusions. Carpenter et al. (2009) found that an icv injection of CRF increased victory chances in dyadic interactions and decreased latency to attack in winners but also reduced aggressive interactions. However, Backström et al. (2011a) found, using similar injection and doses, that CRF induced subordinance during dyadic interactions but saw no effect on number of attacks or latency to attack. However, the longevity of fights might be involved since Carpenter et al. used $15 \mathrm{~min}$ and Backström et al. used $60 \mathrm{~min}$ of social interactions.
Further, no modulating effects on aggression could be seen either by UI, the CRF-R antagonists $\alpha$-helical $\mathrm{CRH}_{1-41}$, or antalarmin (Backström et al., 2011a).

Studies applying administration of exogenous CRF have also shown that CRF is involved in anxiety-like behavior during social interactions (Arregi et al., 2006). In an early study on rats, icv injection of CRF reduced the number of social interactions indicating an anxiogenic effect (Dunn and File, 1987). Anxiety-like behavior in socially defeated male rats is reduced by injection of antisense oligodeoxynucleotide for CRF-R1 (Liebsch et al., 1995). Similarly, CRF and sauvagine reduces sociability in male mice (Mele et al., 1987). Urocortin-2 intraperitoneally injected is anxiogenic in prairie voles (Microtus ochrogaster) as indicated by increasing spontaneous parental behavior following injection (Samuel et al., 2008). In addition, icv administration of urocortin-3 as well as the CRF-R1 agonist, stressin $_{1}$-A, in rats also induces anxiety-like behavior (Zhao et al., 2007). However, the sodium lactate-induced panic-like behavior in male rats during social interaction test can be blocked by the CRF-R1 antagonist antalarmin injected intraperitoneally (Shekhar et al., 2011). Further, injections of CRF and urocortin-1 into the basolateral amygdala reduces social interactions and thus indicating an anxiety-like behavior (Rainnie et al., 2004; Spiga et al., 2006), and the CRF-R1 specific antagonist NBI3b1996 injected into the basolateral nucleus of the amygdala attenuates the anxietylike behavior (Gehlert et al., 2005). Single and repeated injections of urocortin-1 into the bed nucleus of the stria terminalis induce anxiety-like behavior during social interaction test in male rats (Lee et al., 2008), indicating a difference in function between basolateral amygdala and bed nucleus of the stria terminalis. Thus, there is evidence of involvement of both CRF-R1 and CRF-R2 in anxiety-like behavior in mammals, but CRFR1 seems to be most important for this effect. It seems as if the anxiety-like behavior expressed in vertebrates is well conserved since it has been reported in teleost fish as well. In rainbow trout, icv injections of CRF or UI have been shown to induce an anxiety-like behavior similar to a non-ambulatory motor activity in rodents both in isolation and in dyadic interactions (Carpenter et al., 2007, 2009; Backström et al., 2011a). However, no effects of CRF antagonists could be seen, including antalarmin, which has been shown to reduce avoidance behavior in crucian carp (Carassius carassius) (Lastein et al., 2008).

\section{INTERMITTENT EFFECTS OF CRF-EXPRESSION STUDIES}

Social stressors affect gene expression in the CRF system. Because of the involvement in the HPA-axis an up-regulation of CRF expression would be expected. This can also be seen in several studies using social isolation. For instance, socially isolated male rats have more CRF immuno-reactive cells expressed in the median eminence of the hypothalamus following an acute stressor compared to controls (Sánchez et al., 1998). Similarly, in prairie voles (Microtus ochrogaster), social stressors lead to an upregulation of the CRF cell number and mRNA expressions in the PVN. Socially isolated females had more CRF immuno-reactive cells in the PVN after social defeat (Grippo et al., 2007), socially isolated males had higher CRF mRNA expression in the PVN 
compared to paired males (Pan et al., 2009), and in both genders social isolation led to higher density of CRF immuno-reactive cells in the PVN compared to voles paired with a con-specific (Ruscio et al., 2007). Similarly, isolation stress for at least $24 \mathrm{~h}$ and other stressors elevates CRF mRNA expression in the POA of rainbow trout (Doyon et al., 2005), and isolation for $24 \mathrm{~h}$ and $96 \mathrm{~h}$ lead to up-regulation of both CRF and UI mRNA expression in the POA of rainbow trout (Bernier et al., 2008). Thus, an activation of the PVN/POA CRF cell population is apparent after isolation stress. A similar up-regulation of CRF expression can be seen in dominance hierarchies as well. In a 14 days exposure to a visible burrow system in male rats (groups of five males and two females), subordinate males had higher CRF mRNA expression in the central amygdala compared to dominants and controls, and a subset of subordinate males (subordinate responders) had higher CRF mRNA expression in the PVN (Albeck et al., 1997). The subordinate responders were individuals responding with a higher corticosterone response compared to controls and dominants. However, 35 days of social defeat in tree shrews (Tupaia belangeri) also lead to fewer urocortin 1 immuno-reactive cells in the neuron population of the Edinger-Westphal nucleus and fewer CRF immuno-reactive cells in the parvocellular PVN and central amygdala (CeA) (Kozicz et al., 2008). Therefore, it seems that social defeat affects CRF expression in the PVN differently over time, and a similar pattern can be seen in teleost fish. In subordinate rainbow trout, CRF expression is up-regulated in the POA following $8 \mathrm{~h}$ interactions but not after $24 \mathrm{~h}$ interactions (Bernier et al., 2008). However, the time course for effects on CRF expression seems to be complex, since in another experiment rainbow trout being socially subordinate for $72 \mathrm{~h}$ show an up-regulation of CRF expression in the POA (Doyon et al., 2003). Further, after 5 days of social interactions, there were no differences in telencephalic or POA, CRF, or CRF-BP expression between dominant and subordinate rainbow trout (Jeffrey et al., 2012).

Differences between interacting individuals can also be seen in other regions of the brain. For instance, socially defeated male rats have lower CRF levels in the hippocampus (Panksepp et al., 2007). Further, in zebrafish (Danio rerio) the CRF mRNA levels are higher in the telencephalon of subordinate males (but not females) on day 1 of social interactions (Filby et al., 2010b). Similarly, CRF was up-regulated in the telencephalon of male subordinates, but CRF was also down-regulated in the hypothalamus of subordinate males and females following one day of social interactions (Filby et al., 2010a). However, after 5 days of social interactions, no difference in brain CRF mRNA could be seen in zebrafish (Filby et al., 2010b; Pavlidis et al., 2011). In Astatotilapia burtoni interacting for 4 weeks establishing territorial and non-territorial males, very similar to dominants and subordinates, respectively, whole brain CRF as well as pituitary CRF-R1 are down-regulated whereas CRF-BP is up-regulated in non-territorial males (Chen and Fernald, 2008). Further, visual contact for 3 days, but not 1 or 7 days, kept CRF, CRF-R2, and CRF-BP up-regulated whereas CRF-R1 was down-regulated in the brain of non-territorial males compared to controls (Chen and Fernald, 2011). Finally, Senegalese sole (Solea senegalensis) kept at high density for 33 days increase brain CRF mRNA expression as well as plasma cortisol levels compared to fish kept at low density, but no differences were seen in CRF-BP (Wunderink et al., 2011). All these differences are difficult to interpret, but are based on different brain parts. However, it is clear, as seen in zebrafish, rainbow trout, and Astatotilapia burtoni, that the effects of social interaction on CRF expression changes over time. This could be due to several different mechanisms, but aggressive behavior has been shown to be reduced over time in dyadic interacting zebrafish (Pavlidis et al., 2011), suggesting that social stress may decrease over time in interacting fish. Thus, the expression pattern of CRF in the brain is not universal and could be species-, context-, and time-dependent. It also seems that social stressors also sensitize the HPA axis. Icv injections of CRF into isolated rats lead to a higher increase of plasma corticosterone compared to controls (Serra et al., 2005). Similarly, rats socially defeated 2 days consecutively respond with more ACTH release after intravenous CRF injections after 7 days (Buwalda et al., 1999). However, this effect was not apparent at 21 days after social defeat (Buwalda et al., 1999). Thus, it seems as if the sensitization is only occurring during acute stressors and is probably down-regulated by the negative feedback system of the HPA axis.

The modulating effects of CRF are mediated by the CRFreceptors, which are responsible for separate responses. For instance, in socially defeated rats, injection with antisense CRF-R1 reduced anxiety-like behavior in the elevated plus maze, whereas antisense CRF-R2 increased immobility in forced swim test (Liebsch et al., 1999). Further, socially defeated CRF-R1 deficient mice had less impaired spatial memory compared to wild type mice (Wang et al., 2011), indicating that CRF-R1 promotes deleterious effects during social stress. In CRF-R2 knockout mice, aggression is increased, as indicated by a shorter latency to first attack and a higher number of attacks performed (Coste et al., 2006). Similarly, aggression in urocortin-2 knockout male mice is lower than in wild-type mice as measured by higher latency to first attack and more time in passive social contact (Breu et al., 2012). This indicates that CRF-R2 would be involved in the modulation of aggression. However, since socially isolated female prairie voles down-regulates CRF-R2 expression in the hypothalamus and up-regulates CRF-R2 expression in the hippocampus (Pournajafi-Nazarloo et al., 2009), and socially defeated rats seem to have up-regulated CRF-R2 mRNA in the posterior medial amygdala (Fekete et al., 2009), these effects could be site specific.

\section{CHRONIC EFFECTS OF CRF-EARLY LIFE STRESS MODULATING ADULT BEHAVIOR}

Exposure to early life stress can have long-term effects on the development of neuroendocrine systems. These effects have been shown to increase risk for anxiety-like and depressive-like disorders in adulthood in humans [see Veenema (2009) and references therein]. Since CRF has been implied as being involved in anxiety-like behaviors, studies concerning its involvement in early life stress effects have been performed. One of the common models in studying early life stress is using the social stressor of maternal separation in different regimes. For instance, male rats suffering maternal separation and isolation through preadolescence and then re-socialized until early adulthood express several different anxiety-like behaviors, such as shorter duration of social interaction and longer duration of freezing (Lukkes 
et al., 2009a). Similarly, maternal separation for $3 \mathrm{~h}$ a day during pre-adolescence and then being re-socialized in groups of three induces the anxiety-like behaviors shown in elevated plus maze in male rats (Babygirija et al., 2012). The maternal separation and then re-socialization also induce a higher expression of CRF cells in the PVN as well as in the parvocellular division of PVN following a restraint stressor for 5 consecutive days (Babygirija et al., 2012), indicating a more sensitized HPA axis in these rats. However, most of these effects could be ameliorated if the animal is re-socialized with naïve rats. Further, in male prairie voles, social isolation for 6 weeks post-weaning increased anxiety-like behavior in elevated plus maze and increased CRF mRNA levels in the PVN (Pan et al., 2009). Thus, it seems that early life stress increases anxiety-like behaviors as well as sensitizes the HPA axis in adulthood. The anxiety-like behavior seems to be controlled by the CRF-R2. For instance, in male rats going through the maternal separation and then re-socialization, the anxiety-like behavior is reduced by injection of a general CRF antagonist (D-Phe$\left.\mathrm{CRF}_{(12-41)}\right)$ into the dorsal raphe nucleus (Lukkes et al., 2009a) and the CRF-R2 expression is up-regulated in the dorsal raphe nucleus (Lukkes et al., 2009b). Further studies showed that the specific CRF-R1 antagonist antalarmin and the specific CRF-R2 antagonist anti-sauvagine injected into the dorsal raphe nucleus both modulated the induced anxiety-like behaviors. However, anti-sauvagine reversed all anxiety-like behavior whereas antalarmin only had minor effects (Bledsoe et al., 2011). These studies all indicate that CRF-R2 in the dorsal raphe nucleus is involved in the anxiety-like behavior modulation following early life stress. However, in a study using wild-type and CRF-R2 knockout mice in a context fear memory study, maternal separation and isolation post-weaning induced more fear responses in wild-type and knockouts as compared to controls reared in groups of three (Gresack et al., 2010), thus indicating other pathways inducing fear and anxiety.

\section{STRAIN DIFFERENCES-THE IMPACT OF CRF ON STRESS COPING STYLES}

In mammals, divergent stress responses can be consistent over context and time. The behavioral and physiological responses to stress can generally be divided into two coping styles, namely proactive and reactive stress coping (Koolhaas et al., 1999, 2007). Proactive animals are more active, behave more aggressively, and readily form behavioral routines as compared to reactive animals (see Table 1). Moreover, proactive animals show lower HPA axis reactivity but higher sympathetic reactivity than reactive animals. Since divergent coping styles appear related to differences HPAaxis reactivity and locomotory activity, which are both under the control of CRF [see reviews by Heinrichs and Koob (2004) and Lowry and Moore (2006)], differences in the CRF system should be apparent.

Few studies in mammals have addressed this possible link. However, rodents with similar differences in stress responsiveness have been studied. For instance, rats bred for high anxiety behavior (HAB) or low anxiety behavior (LAB) also seem to differ in stress coping style (Landgraf and Wigger, 2002). The $\mathrm{HAB}$ rats seem to be more passive and have a higher HPA axis reactivity, thus fitting nicely into the reactive stress coping style. Interestingly, there seems to be differences in the CRF system between $\mathrm{HAB}$ and $\mathrm{LAB}$ rats. During basal conditions, $\mathrm{HAB}$ rats display lower CRF mRNA in the bed nucleus of the stria terminalis, but higher CRF-R2 expression in the PVN and the ventromedial hypothalamus than LAB rats (Wigger et al., 2004). Following stress, HAB rats show higher CRF-R2 expression in the ventromedial hypothalamus and the central amygdala (Wigger et al., 2004) as compared to LAB rats. Thus, differences in stress coping style seem to be reflected in differences in the CRF system. Similarly, in rats subjected to social defeat for 7 days, the behavioral reactivity could be divided into short latency (SL) or long latency (LL) to assume submissive posture (Wood et al., 2010). These two groups also fit nicely with reactive and proactive stress coping styles, respectively. CRF mRNA densities in the PVN and CRF-R1 levels in the pituitary were decreased in the SL rats compared to controls $24 \mathrm{~h}$ after last social defeat (Wood et al., 2010). Further, in mice strains selected for aggressiveness based on long attack latency (LAL) or short attack latency (SAL), no difference in CRF mRNA in PVN was noted during basal conditions, but $24 \mathrm{~h}$ after a swim stress LAL mice had higher CRF expression in the PVN than basal LAL and stressed SAL (Veenema et al., 2003). Socially defeated mice could be divided into active (proactive) or passive (reactive) coping, and the active coping mice had higher CRF mRNA levels in the hypothalamus than passive or control mice $1 \mathrm{~h}$ after social stress (De Miguel et al., 2011). Several of these differences in the CRF system also make sense concerning the stress coping styles, although differences once again are dependent on time. The reactive stress coping style having a more sensitized CRF system, including elevated CRF and CRF-R1 expression in the PVN during acute social stressor, leading to a higher HPA-axis reactivity. Similarly, high CRF expression in mice reduces aggression.

In recent years, studies on teleost fish have established the existence of stress coping styles in several different species such as halibut (Hippoglossus hippoglossus) (Kristiansen and Fernö, 2007), Nile tilapia (Oreochromis niloticus) (Barreto and Volpato, 2011), and Senegalese sole (Silva et al., 2010). Further, salmonid species have been examined thoroughly. For instance, in brown trout (Salmo trutta) individuals clustered into two separate stress coping styles based on the plasma levels of noradrenaline

Table 1 | Summary of the behavioral and physiological differences between proactive and reactive animals.

\begin{tabular}{lll}
\hline & Proactive & Reactive \\
\hline BEHAVIORAL CHARACTERISTICS & & \\
Aggression & High & Low \\
Conditioned immobility & Low & High \\
Routine formation & High & Low \\
PHYSIOLOGICAL CHARACTERISTICS & Low & High \\
HPA axis reactivity & Low & High \\
Parasympathetic reactivity & High & Low \\
Sympathetic reactivity & & \\
\hline
\end{tabular}

Modified from Koolhaas et al. (1999, 2007) and Øverli et al. (2007) and references therein. 
and adrenaline post-confinement and behavior during hypoxia (Brelin et al., 2005). Similarly, in rainbow trout aggression, dominance and post-stress plasma levels of cortisol differed between individuals and resulted in two distinct coping styles (Schjolden et al., 2005b). Further, two selected strains of rainbow trout representing high responders (HR) and low responders (LR) with respect to plasma cortisol concentrations following a standardized confinement stress were studied by Pottinger and Carrick (1999). Over a series of experiments, these strains were shown to correspond to reactive and proactive stress coping strategy, respectively [see review by Øverli et al. (2007)]. A recent study presented results suggesting divergent effects of stress on the CRF system in HR and LR trout (Backström et al., 2011b). HR trout subjected to confinement stress for $180 \mathrm{~min}$ showed higher CRF mRNA levels than LR trout exposed to the same stressor, and following a $30 \mathrm{~min}$ confinement $\mathrm{HR}$ trout displayed higher CRF-R1 and lower CRF-R2 mRNA levels than LR trout (Backström et al., 2011b). Most likely, these differences are related to the divergent stress coping styles expressed by HR and LR trout. For instance, CRF has been reported to reduce feed intake in teleost fish (De Pedro et al., 1993; Bernier and Peter, 2001), and following a stressful challenge LR fish regain feed intake faster than the HR fish (Øverli et al., 2002). Thus, the higher expression of CRF mRNA in the HR strain during stress could mediate an anorexic effect in the HR strain. Further, CRF has been reported to increase locomotor activity in teleost fish (Clements et al., 2002; Clements and Schreck, 2004). Previous reports have shown diverging activity between the HR and LR fish. The HR fish has been reported to have lower or higher activity than the LR fish (Øverli et al., 2002; Schjolden et al., 2005a, 2006; Backström et al., 2011b). These effects appear to be inconsistent and could be context based. It appears as if LR fish show higher activity during non-stressful, whereas HR fish show higher activity during stressful conditions. The HR fish displayed lower activity when kept in groups in large tanks, in open field, and during isolation (Øverli et al., 2002; Schjolden et al., 2005a, 2006) but showed higher activity during resident-intruder tests (Øverli et al., 2002) and when in confinement (Backström et al., 2011b). This divergence between strains concerning activity could be due to the differences in the stress-induced effects on CRF release. Furthermore, CRF is involved in the control of aggressive behavior and has been reported to suppress aggressive behavior in rainbow trout (Backström et al., 2011a). This means that the diverging neuroendocrine stress responses between strains

\section{REFERENCES}

Albeck, D. S., McKittrick, C. R., Blanchard, D. C., Blanchard, R. J., Nikulina, J., McEwen, B. S., et al. (1997). Chronic social stress alters levels of corticotropin-releasing factor and arginine vasopressin mRNA in rat brain. J. Neurosci. 17, 4895-4903.

Alderman, S. L., and Bernier, N. J. (2007). Localization of corticotropin-releasing factor, urotensin I, and CRF-binding protein gene expression in the brain of the zebrafish, "Danio rerio". J. Comp. Neurol. 502, 783-793. doi: 10.1002/cne. 21332

Aloisi, A. M., Bianchi, M., Lupo, C., Sacerdote, P., and Farabollini, F. (1999). Neuroendocrine and behavioral effects of CRH blockade and stress in male rats. Physiol. Behav. 66, 523-528. doi: 10.1016/S00319384(98)00320-5

Arai, M., Assil, I. Q., and Abou-Samra, A. B. (2001). Characterization of three corticotropin-releasing factor receptors in catfish: a

could explain strain related differences in aggression. The HR strain has been proposed to be less aggressive. For instance, Pottinger and Carrick (2001) reported that when interacting in size matched pairs, HR fish became subordinate significantly more often than LR fish. In addition, the higher locomotor activity shown by LR fish when reared in larger groups was suggested to be caused by high levels of agonistic interaction (Schjolden et al., 2006).

\section{CONCLUDING REMARIS}

CRF and its related peptides are involved in several behavioral and physiological responses to social stressors. These modulating effects are likely to be mediated through several different mechanisms and neuronal structures. The PVN/POA is involved in the HPA/HPI axis regulation through the CRF-R1. Both CRF-R1 and CRF-R2 seems to modulate the behavioral responses to social stress, such as aggression and anxiety-like behavior. Specifically, CRF-R1 seems to be more directly involved in modulating anxiety-like behavior, whereas CRF-R2 has more pronounced effects on aggressive behavior. However, some studies have also seen modulating effects of CRF-R1 on aggressive behavior. The effects of early life stress on stress responsiveness and anxiety-like behavior in adulthood appear to be at least in part mediated by CRF-R2 expressed in the dorsal raphe nucleus. Finally, differences in the CRF system is probably one factor responsible for the differences observed in behavioral profiles and stress responses of individuals displaying divergent stress coping styles. Since most of these studies have been performed on juvenile teleost fish and male rodents, further studies are needed to elucidate if there are also gender differences in the CRF system. Furthermore, the links between CRF and several other pathways including the vasopressinergic and monoaminergic systems are needed for a better understanding of the effects of social stress on behavior and physiology.

\section{ACKNOWLEDGMENTS}

We would like to thank Martina Heynen for commenting an earlier draft of this manuscript. The work was supported by the Swedish Research Council for Environment, Agriculture science and Spatial planning (FORMAS, to Svante Winberg and Tobias Backström), The Swedish Research Council (VR, to Svante Winberg) and the European Community's Seventh Framework Programme (FP7/2010-2014) under Grant Agreement No. 265957-COPEWELL (to Svante Winberg).

novel third receptor is predominantly expressed in pituitary and urophysis. Endocrinology 142, 446-454. doi: 10.1210/en. 142.1.446

Arregi, A., Azpiroz, A., Fano, E., and Garmendia, L. (2006). Aggressive behavior: implications of dominance and subordination for the study of mental disorders. Aggress. Violent Behav. 11, 394-413. doi: 10.1016/j.avb.2006.01.005

Babygirija, R., Yoshimoto, S., Gribovskaja-Rupp, I., Bülbül,
M., Ludwig, K., and Takahashi, T. (2012). Social interaction attenuates stress responses following chronic stress in maternally separated rats. Brain Res. 1469, 54-62. doi: 10.1016/j.brainres.2012. 06.007

Backström, T., Pettersson, A., Johansson, V., and Winberg, S. (2011a). CRF and urotensin I effects on aggression and anxietylike behavior in rainbow trout. J. Exp. Biol. 214, 907-914. doi: 10.1242/jeb. 045070 
Backström, T., Schjolden, J., Øverli, Ø., Thörnqvist, P. O., and Winberg, S. (2011b). Stress effects on AVT and CRF systems in two strains of rainbow trout (Oncorhynchus mykiss) divergent in stress responsiveness. Horm. Behav. 59, 180-186. doi: 10.1016/j.yhbeh.2010.11.008

Bale, T. L., Contarino, A. B., Smith, G. W., Chan, R., Gold, L. H., Sawchenko, P. E., et al. (2000). Mice deficient for corticotropinreleasing hormone receptor-2 display anxiety-like behaviour and are hypersensitive to stress. Nat. Genet. 24, 410-414. doi: 10.1038/74263

Bale, T. L., Lee, K.-F., and Vale, W. W. (2002a). The role of corticotropinreleasing factor receptors in stress and anxiety. Integr. Comp. Biol. 42, 552-555. doi: 10.1093/icb/ 42.3.552

Bale, T. L., Picetti, R., Contarino, A., Koob, G. F., Vale, W. W., and Lee, K.-F. (2002b). Mice deficient for both corticotropin-releasing factor receptor 1 (CRFR1) and CRFR2 have an impaired stress response and display sexually dichotomous anxiety-like behavior. J. Neurosci. 22, 193-199.

Bale, T. L., and Vale, W. W. (2004). CRF and CRF receptors: role in stress responsivity and other behaviors. Annu. Rev. Pharmacol. Toxicol. 44, 525-557. doi: 10.1146/annurev. pharmtox.44.101802.121410

Barreto, R. E., and Volpato, G. L. (2011). Ventilation rates indicate stress-coping styles in Nile tilapia. J. Biosci.36, 851-855. doi: 10.1007/s12038-011-9111-4

Behan, D. P., Cepoi, D., Fischer, W. H., Park, M., Sutton, S., Lowry, P. J., et al. (1996). Characterization of a sheep brain corticotropin releasing factor binding protein. Brain Res. 709, 265-274. doi: 10.1016/00068993(95)01317-2

Bernier, N. J., Alderman, S. L., and Bristow, E. N. (2008). Heads or tails? Stressor-specific expression of corticotropin-releasing factor and urotensin I in the preoptic area and caudal neurosecretory system of rainbow trout. J. Endocrinol. 196, 637-648. doi: 10.1677/JOE-07-0568

Bernier, N. J., Lin, X., and Peter, R. E. (1999). Differential expression of corticotropin-releasing factor $(\mathrm{CRF})$ and urotensin i precursor genes, and evidence of CRF gene expression regulated by cortisol in goldfish brain. Gen. Comp. Endocrinol. 116, 461-477. doi: 10.1006/gcen.1999.7386

Bernier, N. J., and Peter, R. E. (2001). Appetite-suppressing effects of urotensin I and corticotropin-releasing hormone in goldfish (Carassius auratus). Neuroendocrinology 73, 248-260. doi: $10.1159 / 000054642$

Blanchard, D. C., Sakai, R. R., McEwen, B., Weiss, S. M., and Blanchard, R. J. (1993). Subordination stress: behavioral, brain, and neuroendocrine correlates. Behav. Brain Res. 58, 113-121. doi: 10.1016/01664328(93)90096-9

Blanchard, R. J., McKittrick, C. R., and Blanchard, D. C. (2001). Animal models of social stress: effects on behavior and brain neurochemical systems. Physiol. Behav. 73, 261-271. doi: 10.1016/S0031-9384(01)00449-8

Bledsoe, A. C., Oliver, K. M., Scholl, J. L., and Forster, G. L. (2011). Anxiety states induced by postweaning social isolation are mediated by CRF receptors in the dorsal raphe nucleus. Brain Res. Bull. 85, 117-122. doi: $\quad 10.1016 / j . b r a i n r e s b u l l .2011$. 03.003

Bloom, F. E., Battenberg, E. L. F., Rivier, J., and Vale, W. (1982). Corticotropin releasing factor (CRF): immunoreactive neurones and fibers in rat hypothalamus. Regul. Pept. 4, 43-48. doi: 10.1016/0167-0115(82)90107-0

Brelin, D., Petersson, E., and Winberg, S. (2005). Divergent stress coping styles in juvenile brown trout (Salmo trutta). Ann. N.Y. Acad. Sci. 1040, 239-245. doi: 10.1196/annals.1327.033

Breu, J., Touma, C., Hölter, S. M., Knapman, A., Wurst, W., and Deussing, J. M. (2012). Urocortin 2 modulates aspects of social behaviour in mice. Behav. Brain Res. 233, 331-336. doi: 10.1016/j.bbr.2012.05.031

Britton, K. T., Lee, G., Vale, W., Rivier, J., and Koob, G. F. (1986). Corticotropin releasing factor (CRF) receptor antagonist blocks activating and 'anxiogenic' actions of CRF in the rat. Brain Res. 369, 303-306. doi: 10.1016/0006-8993(86)90539-1

Buwalda, B, de Boer, S. F., Schmidt, E. D., Felszeghy, K., Nyakas, C., Sgoifo, A., et al. (1999). Longlasting deficient dexamethasone suppression of hypothalamicpituitary-adrenocortical activation following peripheral CRF challenge in socially defeated rats. J. Neuroendocrinol. 11, 513-520.

Cannon, W. B. (1915). Bodily Changes in Pain, Hunger, Fear and Rage: An Account of Recent Researches into the Function of Emotional Excitement.
New York, NY: Appleton. doi: 10.1037/10013-000

Carpenter, R. E., Korzan, W. J., Bockholt, C., Watt, M. J., Forster, G. L., Renner, K. J., et al. (2009). Corticotropin releasing factor influences aggression and monoamines: modulation of attacks and retreats. Neuroscience 158, 412-425. doi: 10.1016/j.neuroscience.2008.10.014

Carpenter, R. E., Watt, M. J., Forster, G. L., Overli, O., Bockholt, C., Renner K. J., et al. (2007). Corticotropin releasing factor induces anxiogenic locomotion in trout and alters serotonergic and dopaminergic activity. Horm. Behav. 52, 600-611. doi 10.1016/j.yhbeh.2007.07.012

Carrasco, G. A., and Van De Kar, L. D. (2003). Neuroendocrine pharmacology of stress. Eur. J. Pharmacol. 463, 235-272. doi: 10.1016/S00142999(03)01285-8

Chang, C.-P., Pearse, R. V., O'Connell, S., and Rosenfeld, M. G. (1993). Identification of a seven transmembrane helix receptor for corticotropin-releasing factor and sauvagine in mammalian brain. Neuron 11, 1187-1195. doi 10.1016/0896-6273(93)90230-O

Chen, C.-C., and Fernald, R. D (2008). Sequences, expression patterns and regulation of the corticotropin-releasing factor system in a teleost. Gen. Comp. Endocrinol. 157, 148-155. doi 10.1016/j.ygcen.2008.04.003

Chen, C.-C., and Fernald, R. D. (2011). visual information alone changes behavior and physiology during social interactions in a cichlid fish (Astatotilapia burtoni). PLoS ONE 6:e20313. doi: 10.1371/journal.pone.0020313

Chen, R., Lewis, K., Perrin, M., and Vale, W. (1993). Expression cloning of a human corticotropinreleasing-factor receptor. Proc. Natl. Acad.Sci. U.S.A. 90, 8967-8971. doi: 10.1073/pnas.90.19.8967

Clements, S., and Schreck, C. B. (2004). Central administration of corticotropin-releasing hormone alters downstream movement in an artificial stream in juvenile Chinook salmon (Oncorhynchus tshawytscha). Gen. Comp. Endocrinol. 137, 1-8. doi: 10.1016/j.ygcen.2004.02.004

Clements, S., Schreck, C. B., Larsen, D. A., and Dickhoff, W. W. (2002). Central administration of corticotropin-releasing hormone stimulates locomotor activity in juvenile Chinook salmon (Oncorhynchus tshawytscha). Gen. Comp. Endocrinol. 125, 319-327. doi: $10.1006 /$ gcen.2001.7707
Cooper, M., and Huhman, K. (2007). Corticotropin-releasing factor receptors in the dorsal raphe nucleus modulate social behavior in Syrian hamsters. Psychopharmacology 194, 297-307. doi: 10.1007/s00213-007-0849-1

Cooper, M. A., and Huhman, K. L. (2010). Blocking corticotropinreleasing factor-2 receptors, but not corticotropin-releasing factor1 receptors or glucocorticoid feedback, disrupts the development of conditioned defeat. Physiol. Behav. 101, 527-532. doi: 10.1016/j.physbeh.2010.08.003

Cortright, D. N., Nicoletti, A., and Seasholtz, A. F. (1995). Molecular and biochemical characterization of the mouse brain corticotropinreleasing hormone-binding protein Mol. Cell. Endocrinol. 111, 147-157. doi: 10.1016/0303-7207(95) 03558-O

Coste, S. C., Heard, A. D., Phillips, T. J., and Stenzel-Poore, M. P. (2006). Corticotropin-releasing factor receptor type 2-deficient mice display impaired coping behaviors during stress. Genes Brain Behav. 5, 131-138. doi: 10.1111/j.1601183X.2005.00142.x

Coste, S. C., Kesterson, R. A., Heldwein, K. A., Stevens, S. L., Heard, A. D., Hollis, J. H., et al. (2000). Abnormal adaptations to stress and impaired cardiovascular function in mice lacking corticotropin-releasing hormone receptor-2. Nat. Genet. 24, 403-409. doi: 10.1038/74255

D'anna, K. L., Stevenson, S. A., and Gammie, S. C. (2005). Urocortin 1 and 3 impair maternal defense behavior in mice. Behav. Neurosci. 119, 1061-1071. doi: 10.1037/07357044.119.4.1061

De Miguel, Z., Vegas, O., Garmendia, L., Arregi, A., Beitia, G., and Azpiroz, A. (2011). Behavioral coping strategies in response to social stress are associated with distinct neuroendocrine, monoaminergic and immune response profiles in mice. Behav. Brain Res. 225, 554-561. doi: 10.1016/j.bbr.2011.08.011

De Pedro, N., Alonso-Gomez, A. L., Gancedo, B., Delgado, M. J., and Alonso-Bedate, M. (1993). Role of corticotropinreleasing factor (CRF) as a food intake regulator in goldfish. Physiol. Behav. 53, 517-520. doi: 10.1016/0031-9384(93)90146-7

Delville, Y., Stires, C., and Ferris, C. F. (1992). Distribution of corticotropin-releasing hormone immunoreactivity in golden hamster brain. Brain 
Res. Bull. 29, 681-684. doi: 10.1016/0361-9230(92)90138-N

Donaldson, C., Sutton, S., Perrin, M., Corrigan, A., Lewis, K., Rivier, J., et al. (1996). Cloning and characterization of human urocortin. Endocrinology 137, 2167-2170. doi: 10.1210/en.137.5.2167

Doyon, C., Gilmour, K. M., Trudeau, V. L., and Moon, T. W. (2003). Corticotropin-releasing factor and neuropeptide $\mathrm{Y}$ mRNA levels are elevated in the preoptic area of socially subordinate rainbow trout. Gen. Comp. Endocrinol. 133, 260-271. doi: 10.1016/S0016-6480(03)00195-3

Doyon, C., Trudeau, V. L., and Moon, T. W. (2005). Stress elevates corticotropin-releasing factor (CRF) and CRF-binding protein mRNA levels in rainbow trout (Oncorhynchus mykiss). J. Endocrinol. 186, 123-130. doi: 10.1677/joe. 1.06142

Dunn, A. J., and File, S. E. (1987). Corticotropin-releasing factor has an anxiogenic action in the social interaction test. Horm. Behav. 21, 193-202. doi: 10.1016/0018-506X(87)90044-4

Elkabir, D. R., Wyatt, M. E., Vellucci, S. V., and Herbert, J. (1990). The effects of separate or combined infusions of corticotrophinreleasing factor and vasopressin either intraventricularly or into the amygdala on aggressive and investigative behaviour in the rat. Regul. Pept. 28, 199-214. doi: $\quad 10.1016 / 0167-0115(90)$ 90018-R

Farrokhi, C., Blanchard, D. C., Griebel, G., Yang, M., Gonzales, C., Markham, C., et al. (2004). Effects of the CRF1 antagonist SSR125543A on aggressive behaviors in hamsters. Pharmacol. Biochem. Behav. 77, 465-469. doi: 10.1016/j.pbb.2003.12.023

Fekete, É. M., Zhao, Y., Li, C., Sabino, V., Vale, W. W., and Zorrilla, E. P. (2009). Social defeat stress activates medial amygdala cells that express type 2 corticotropinreleasing factor receptor mRNA. Neuroscience 162, 5-13. doi: 10.1016/j.neuroscience.2009.03.078

Filby, A., Paull, G., Hickmore, T., and Tyler, C. (2010a). Unravelling the neurophysiological basis of aggression in a fish model. BMC Genomics 11:498. doi: 10.1186/1471-2164-11498

Filby, A. L., Paull, G. C., Bartlett, E. J., Van Look, K. J. W., and Tyler, C. R. (2010b). Physiological and health consequences of social status in zebrafish (Danio rerio).
Physiol. Behav. 101, 576-587. doi: 10.1016/j.physbeh.2010.09.004

Gammie, S. C., Negron, A., Newman, S. M., and Rhodes, J. S. (2004) Corticotropin-releasing factor inhibits maternal aggression in mice. Behav. Neurosci. 118, 805-814. doi: 10.1037/0735-7044. 118.4.805

Gehlert, D. R., Shekhar, A., Morin, S. M., Hipskind, P. A., Zink, C., Gackenheimer, S. L., et al. (2005). Stress and central Urocortin increase anxiety-like behavior in the social interaction test via the CRF1 receptor. Eur. J. Pharmacol. 509, 145-153. doi: 10.1016/j.ejphar.2004.12.030

Greenberg, N., Chen, T., and Crews, D. (1984). Social status, gonadal state, and the adrenal stress response in the lizard, Anolis carolinensis. Horm. Behav. 18, 1-11. doi: 10.1016/0018506X(84)90045-X

Gresack, J. E., Risbrough, V. B., Scott, C. N., Coste, S., StenzelPoore, M., Geyer, M. A., et al. (2010). Isolation rearing-induced deficits in contextual fear learning do not require CRF2 receptors. Behav. Brain Res. 209, 80-84. doi: 10.1016/j.bbr.2010.01.018

Grippo, A. J., Gerena, D., Huang, J., Kumar, N., Shah, M., Ughreja, R., et al. (2007). Social isolation induces behavioral and neuroendocrine disturbances relevant to depression in female and male prairie voles. Psychoneuroendocrinology 32, 966-980. doi: 10.1016/j.psyneuen.2007.07.004

Guillemin, R., and Rosenberg, B. (1955). Humoral hypothalamic control of anterior pituitary: a study with combined tissue cultures. Endocrinology 57, 599-607. doi: 10.1210/endo-57-5-599

Hauger, R. L., Grigoriadis, D. E., Dallman, M. F., Plotsky, P. M. Vale, W. W., and Dautzenberg, F. M. (2003). International Union of Pharmacology. XXXVI. current status of the nomenclature for receptors for corticotropinreleasing factor and their ligands. Pharmacol. Rev. 55, 21-26. doi: 10.1124/pr.55.1.3

Heinrichs, S. C., and Koob, G. F. (2004). Corticotropin-releasing factor in brain: a role in activation, arousal, and affect regulation. J. Pharmacol. Exp. Ther. 311, 427-440. doi: 10.1124/jpet.103.052092

Heinrichs, S. C., Lapsansky, J., Lovenberg, T. W., De Souza, E. B., and Chalmers, D. T. (1997). Corticotropin-releasing factor CRF1, but not CRF2, receptors mediate anxiogenic-like behavior.
Regul. Pept. 71, 15-21. doi: 10.1016/S0167-0115(97)01005-7

Huising, M., Metz, Jr., Van Schooten, C., Taverne-Thiele, A., Hermsen, T. Verburg-Van Kemenade, B., et al. (2004). Structural characterisation of a cyprinid (Cyprinus carpio L.) CRH, CRH-BP and CRH-R1, and the role of these proteins in the acute stress response. J. Mol. Endocrinol. 32, 627-648. doi: 10.1677/jme.0.0320627

Huntingford, F. A., and Turner, A. (1987). Animal Conflict. New York, NY: Chapman and Hall.

Ishida, I., Ichikawa, T., and Deguchi, T (1986). Cloning and sequence analysis of cDNA encoding urotensin I precursor. Proc. Natl. Acad. Sci. U.S.A. 83, 308-312. doi: $10.1073 /$ pnas.83.2.308

Jeffrey, J. D., Esbaugh, A. J., Vijayan, M. M., and Gilmour, K. M. (2012). Modulation of hypothalamicpituitary-interrenal axis function by social status in rainbow trout. Gen. Comp. Endocrinol. 176, 201-210. doi: 10.1016/j.ygcen.2012.01.016

Johnson, E. O., Kamilaris, T. C. Chrousos, G. P., and Gold, P. W. (1992). Mechanisms of stress: a dynamic overview of hormonal and behavioral homeostasis. Neurosci. Biobehav. Rev. 16, 115-130. doi: $\quad 10.1016 / S 0149-7634(05)$ 80175-7

Kishimoto, T., Pearse Rv, I., Lin, C., and Rosenfeld, M. (1995). A sauvagine/corticotropin-releasing factor receptor expressed in heart and skeletal muscle. Proc. Natl. Acad. Sci. U.S.A. 92, 1108-1112. doi: $10.1073 /$ pnas.92.4.1108

Koolhaas, J. M., De Boer, S. F. Buwalda, B., and Van Reenen, K. (2007). Individual variation in coping with stress: a multidimensional approach of ultimate and proximate mechanisms. Brain Behav. Evol. 70, 218-226. doi: 10.1159/ 000105485

Koolhaas, J. M., Korte, S. M., De Boer, S. F., Van Der Vegt, B. J., Van Reenen, C. G., Hopster, H., et al. (1999). Coping styles in animals: current status in behavior and stress-physiology. Neurosci. Biobehav. Rev. 23, 925-935. doi: 10.1016/S0149-7634(99)00026-3

Kozicz, T., Bordewin, L. a. P., Czéh B., Fuchs, E., and Roubos, E. W (2008). Chronic psychosocial stress affects corticotropin-releasing factor in the paraventricular nucleus and central extended amygdala as well as urocortin 1 in the non-preganglionic EdingerWestphal nucleus of the tree shrew. Psychoneuroendocrinology 33,
741-754. doi: 10.1016/j.psyneuen. 2008.02.012

Kristiansen, T. S., and Fernö, A. (2007). Individual behaviour and growth of halibut (Hippoglossus hippoglossus L.) fed sinking and floating feed: evidence of different coping styles. Appl. Anim. Behav. Sci. 104, 236-250. doi: 10.1016/j.applanim.2006.09.007

Landgraf, R., and Wigger, A. (2002). High vs low anxiety-related behavior rats: an animal model of extremes in trait anxiety. Behav. Genet. 32, 301-314. doi: 10.1023/A:1020258104318

Lastein, S., Höglund, E., øverli, Ø., and Døving, K. (2008). Effects of antalarmin, a CRF receptor 1 antagonist, on fright reaction and endocrine stress response in crucian carp (Carassius carassius). J. Comp. Physiol. A Neuroethol. Sens. Neural Behav. Physiol. 194, 1007-1012. doi: 10.1007/s00359-008-0372-9

Lederis, K., Fryer, J. N., and Yulis, C. R. (1985). The fish neuropeptide urotensin I: its physiology and pharmacology. Peptides 6, 353-361. doi: 10.1016/0196-9781(85)90397-3

Lederis, K., Letter, A., McMaster D., Moore, G., and Schlesinger, D. (1982). Complete amino acid sequence of urotensin I, a hypotensive and corticotropinreleasing neuropeptide from Catostomus. Science 218, 162-165. doi: 10.1126/science.6981844

Lee, Y., Fitz, S., Johnson, P. L., and Shekhar, A. (2008). Repeated stimulation of CRF receptors in the BNST of rats selectively induces social but not panic-like anxiety. Neuropsychopharmacology 33, 2586-2594. doi: 10.1038/sj.npp. 1301674

Lewis, K., Li, C., Perrin, M. H., Blount, A., Kunitake, K., Donaldson, C., et al. (2001). Identification of urocortin III, an additional member of the corticotropin-releasing factor (CRF) family with high affinity for the CRF2 receptor. Proc. Natl. Acad. Sci. U.S.A. 98, 7570-7575. doi: $10.1073 /$ pnas. 121165198

Liebsch, G., Landgraf, R., Engelmann, M., Lorscher, P., and Holsboer, F. (1999). Differential behavioural effects of chronic infusion of $\mathrm{CRH}$ 1 and $\mathrm{CRH} 2$ receptor antisense oligonucleotides into the rat brain. J. Psychiatr. Res. 33, 153-163. doi: 10.1016/S0022-3956(98)80047-2

Liebsch, G., Landgraf, R., Gerstberger, R., Probst, J. C., Wotjak, C. T., Engelmann, M., et al. (1995). Chronic infusion of a CRH1 receptor antisense oligodeoxynucleotide into the central nucleus of the 
amygdala reduced anxiety-related behavior in socially defeated rats. Regul. Pept. 59, 229-239. doi: 10.1016/0167-0115(95)00099-W

Lovenberg, T., Liaw, C., Grigoriadis, D., Clevenger, W., Chalmers, D., Souza, E., et al. (1995). Cloning and characterization of a functionally distinct corticotropinreleasing factor receptor subtype from rat brain. Proc. Natl. Acad. Sci. U.S.A. 92, 836-840. doi: 10.1073/pnas.92.3.836

Lowry, C. A., and Moore, F. L. (2006). Regulation of behavioral responses by corticotropin-releasing factor. Gen. Comp. Endocrinol. 146, 19-27. doi: 10.1016/j.ygcen.2005.12.006

Lukkes, J., Vuong, S., Scholl, J., Oliver, H., and Forster, G. (2009a). Corticotropin-releasing factor receptor antagonism within the dorsal raphe nucleus reduces social anxiety-like behavior after early-life social isolation. J. Neurosci. 29, 9955-9960. doi: 10.1523/JNEUROSCI.0854-09.2009

Lukkes, J. L., Summers, C. H., Scholl, J. L., Renner, K. J., and Forster, G. L. (2009b). Early life social isolation alters corticotropin-releasing factor responses in adult rats. Neuroscience 158, 845-855. doi: 10.1016/j.neuroscience.2008.10.036

Luo, X., Kiss, A., Makara, G., Lolait, S. J., and Aguilera, G. (1994). Stressspecific regulation of corticotropin releasing hormone receptor expression in the paraventricular and supraoptic nuclei of the hypothalamus in the rat. J. Neuroendocrinol. 6, 689-696. doi: 10.1111/j.13652826.1994.tb00636.x

Matz, S. P., and Hofeldt, G. T. (1999). Immunohistochemical localization of corticotropinreleasing factor in the brain and corticotropin-releasing factor and thyrotropin-stimulating hormone in the pituitary of Chinook salmon (Oncorhynchus tshawytscha). Gen. Comp. Endocrinol. 114, 151-160. doi: $10.1006 /$ gcen.1999.7253

Mele, A., Cabib, S., Oliverio, A., Melchiorri, P., and Puglisi-Allegra, S. (1987). Effects of corticotropin releasing factor and sauvagine on social behavior of isolated mice. Peptides 8, 935-938. doi: 10.1016/0196-9781(87)90083-0

Montecucchi, P. C., Henschen, A., and Erspamer, V. (1979). Structure of sauvagine, a vasoactive peptide from the skin of a frog. Hoppe-Seylers Z. Physiol. Chem. 360, 1178-1178.

Øverli, Ø., Pottinger, T. G., Carrick, T. R., Øverli, E., and Winberg, S. (2002). Differences in behaviour between rainbow trout selected for high- and low-stress responsiveness. J. Exp. Biol. 205, 391-395.

Øverli, Ø., Sorensen, C., Pulman, K. G. T., Pottinger, T. G., Korzan, W., Summers, C. H., et al. (2007). Evolutionary background for stress-coping styles: relationships between physiological, behavioral, and cognitive traits in nonmammalian vertebrates. Neurosci. Biobehav. Rev. 31, 396-412. doi: 10.1016/j.neubiorev.2006.10.006

Ozawa, M., Oki, Y., Watanabe, F., Iino, K., Masuzawa, M., Iwabuchi, M., et al. (1998). Effect of urocortin and its interaction with adrenocorticotropin (ACTH) secretagogues on ACTH release. Peptides 19, 513-518. doi: $\quad 10.1016 /$ S0196-9781(97) 00464-6

Pan, Y., Liu, Y., Young, K. A., Zhang, Z., and Wang, Z. (2009). Postweaning social isolation alters anxiety-related behavior and neurochemical gene expression in the brain of male prairie voles. Neurosci. Lett. 454, 67-71. doi: 10.1016/j.neulet.2009.02.064

Panksepp, J., Burgdorf, J., Beinfeld, M. C., Kroes, R. A., and Moskal, J. R. (2007). Brain regional neuropeptide changes resulting from social defeat. Behav. Neurosci. 121, 1364-1371. doi: 10.1037/0735-7044.121.6.1364

Paull, W. K., and Gibbs, F. P. (1983). The corticotropin releasing factor (CRF) neurosecretory system in intact, adrenalectomized, and adrenalectomized-dexamethasone treated rats. Histochem. Cell Biol. 78, 303-316. doi: 10.1007/BF00496618

Pavlidis, M., Sundvik, M., Chen, Y.-C., and Panula, P. (2011). Adaptive changes in zebrafish brain in dominant-subordinate behavioral context. Behav. Brain Res. 225, 529-537. doi: 10.1016/j.bbr.2011.08.022

Pelletier, G., Desy, L., Cote, J., and Vaudry, H. (1983). Immunocytochemical localization of corticotropin-releasing factor-like immunoreactivity in the human hypothalamus. Neurosci. Lett. 41, 259-263. doi: 10.1016/0304-3940(83)90460-3

Pepels, P. P. L. M., Meek, J., Bonga, S. E. W., and Balm, P. H. M. (2002). Distribution and quantification of corticotropin-releasing hormone $(\mathrm{CRH})$ in the brain of the teleost fish "Oreochromis mossambicus" (tilapia). J. Comp. Neurol. 453, 247-268. doi: 10.1002/cne.10377

Perrin, M., Donaldson, C., Chen, R., Blount, A., Berggren, T., Bilezikjian, L., et al. (1995). Identification of a second corticotropinreleasing factor receptor gene and characterization of a cDNA expressed in heart. Proc. Natl. Acad. Sci. U.S.A. 92, 2969-2973. doi: 10.1073/pnas.92.7.2969

Perrin, M., Donaldson, C., Chen, R., Lewis, K., and Vale, W. (1993). Cloning and functional expression of a rat brain corticotropin releasing factor (CRF) receptor. Endocrinology 133, 3058-3061. doi 10.1210/en.133.6.3058

Pohl, S., Darlison, M. G., Clarke, W. C., Lederis, K., and Richter, D. (2001) Cloning and functional pharmacology of two corticotropin-releasing factor receptors from a teleost fish. Eur. J. Pharmacol. 430, 193-202. doi: 10.1016/S0014-2999(01)01391-7

Potter, E., Behan, D. P., Fischer, W. H., Linton, E. A., Lowry, P. J., and Vale, W. W. (1991). Cloning and characterization of the cDNAs for human and rat corticotropin releasing factor-binding proteins. Nature 349 , 423-426. doi: 10.1038/349423a0

Pottinger, T. G., and Carrick, T. R. (1999). Modification of the plasma cortisol response to stress in rainbow trout by selective breeding. Gen. Comp. Endocrinol. 116, 122-132. doi: 10.1006/gcen.1999.7355

Pottinger, T. G., and Carrick, T. R. (2001). Stress responsiveness affects dominant-subordinate relationships in rainbow trout. Horm. Behav. 40, 419-427. doi: 10.1006/hbeh.2001.1707

Pournajafi-Nazarloo, H., Partoo, L., Sanzenbacher, L., Paredes, J., Hashimoto, K., Azizi, F., et al. (2009). Stress differentially modulates mRNA expression for corticotrophin-releasing hormone receptors in hypothalamus, hippocampus and pituitary of prairie voles. Neuropeptides 43, 113-123. doi: 10.1016/j.npep.2008.12.002

Raadsheer, F. C., Sluiter, A. A. Ravid, R., Tilders, F. J. H., and Swaab, D. F. (1993). Localization of corticotropin-releasing hormone (CRH) neurons in the paraventricular nucleus of the human hypothalamus; agedependent colocalization with vasopressin. Brain Res. 615, 50-62. doi: 10.1016/0006-8993(93)91113-7

Rainnie, D. G., Bergeron, R., Sajdyk, T. J., Patil, M., Gehlert, D. R., and Shekhar, A. (2004). Corticotrophin releasing factor-induced synaptic plasticity in the amygdala translates stress into emotional disorders. J. Neurosci. 24, 3471-3479. doi: 10.1523/JNEUROSCI.5740-03.2004

Reyes, T. M., Lewis, K., Perrin, M. H., Kunitake, K. S., Vaughan, J., Arias, C. A., et al. (2001). Urocortin
II: a member of the corticotropinreleasing factor (CRF) neuropeptide family that is selectively bound by type 2 CRF receptors. Proc. Natl. Acad. Sci. U.S.A. 98, 2843-2848. doi: 10.1073/pnas.051626398

Robison, C. L., Meyerhoff, J. L., Saviolakis, G. A., Chen, W. K., Rice, K. C., and Lumley, L. A. (2004). A CRH1 antagonist into the amygdala of mice prevents defeat-induced defensive behavior. Ann. N.Y. Acad. Sci. 1032, 324-328. doi: 10.1196/annals.1314.052

Ronan, P. J., and Summers, C. H. (2011). "Molecular signaling and translational significance of the corticotropin releasing factor system," in Brain as a Drug Target, ed S. Rahman (San Diego: Elsevier Academic Press Inc.), 235-292.

Ruscio, M. G., Sweeny, T., Hazelton, J., Suppatkul, P., and Sue Carter, C. (2007). Social environment regulates corticotropin releasing factor, corticosterone and vasopressin in juvenile prairie voles. Horm. Behav. 51, 54-61. doi: 10.1016/j.yhbeh.2006.08.004

Saffran, M., and Schally, A. V. (1955). The release of corticotrophin by anterior pituitary tissue in vitro. Can. J. Biochem. Physiol. 33 , 408-415. doi: 10.1139/055-054

Samuel, P. A., Hostetler, C. M., and Bales, K. L. (2008). Urocortin II increases spontaneous parental behavior in prairie voles (Microtus ochrogaster). Behav. Brain Res. 186, 284-288. doi: 10.1016/j.bbr.2007.08.015

Sánchez, M. M., Aguado, F., SánchezToscano, F., and Saphier, D. (1998). Neuroendocrine and immunocytochemical demonstrations of decreased hypothalamo-pituitaryadrenal axis responsiveness to restraint stress after long-term social isolation. Endocrinology 139, 579-587. doi: 10.1210/en.139.2.579

Sapolsky, R. M. (1990). Adrenocortical function, social rank, and personality among wild baboons. Biol. Psychiatry 28, 862-878. doi 10.1016/0006-3223(90)90568-M

Schjolden, J., Backström, T., Pulman, K. G. T., Pottinger, T. G., and Winberg, S. (2005a). Divergence in behavioural responses to stress in two strains of rainbow trout (Oncorhynchus mykiss) with contrasting stress responsiveness. Horm. Behav. 48, 537-544. doi: 10.1016/j.yhbeh.2005.04.008

Schjolden, J., Stoskhus, A., and Winberg, S. (2005b). Does individual variation in stress responses and agonistic behavior reflect divergent stress coping strategies 
in juvenile rainbow trout? Physiol. Biochem. Zool. 78, 715-723. doi: 10.1086/432153

Schjolden, J., Pulman, K. G. T., Pottinger, T. G., Metcalfe, N. B., and Winberg, S. (2006). Divergence in locomotor activity between two strains of rainbow trout Oncorhynchus mykiss with contrasting stress responsiveness. J. Fish Biol. 68, 920-924. doi: 10.1111/j.0022-1112.2006.00935.x

Seasholtz, A., Valverde, R., and Denver, R. (2002). Corticotropin-releasing hormone-binding protein: biochemistry and function from fishes to mammals. J. Endocrinol. 175, 89-97. doi: 10.1677/joe.0.1750089

Serra, M., Pisu, M. G., Floris, I., and Biggio, G. (2005). Social isolation-induced changes in the hypothalamic-pituitary-adrenal axis in the rat. Stress 8, 259-264. doi: $10.1080 / 10253890500495244$

Shekhar, A., Johnson, P. L., Fitz, S. D., Nakazato, A., Chaki, S., Steckler, T., et al. (2011). A selective, non-peptide CRF receptor 1 antagonist prevents sodium lactateinduced acute panic-like responses. Int. J. Neuropsychopharmacol. 14, 355-365. doi: $10.1017 /$ S1461145710001355

Silva, P. I. M., Martins, C. I. M., Engrola, S., Marino, G., Øverli, Ø., and Conceição, L. E. C. (2010). Individual differences in cortisol levels and behaviour of Senegalese sole (Solea senegalensis) juveniles: evidence for coping styles. Appl. Anim. Behav. Sci. 124, 75-81. doi: 10.1016/j.applanim.2010.01.008

Spiga, F., Lightman, S. L., Shekhar, A., and Lowry, C. A. (2006). Injections of urocortin 1 into the basolateral amygdala induce anxiety-like behavior and c-Fos expression in brainstem serotonergic neurons. Neuroscience 138, 1265-1276. doi: 10.1016/j.neuroscience.2005.12.051

Stenzel, P., Kesterson, R., Yeung, W., Cone, R., Rittenberg, M., and Stenzel-Poore, M. (1995).
Identification of a novel murine receptor for corticotropin-releasing hormone expressed in the heart. Mol. Endocrinol. 9, 637-645. doi: 10.1210/me.9.5.637

Swanson, L. W., Sawchenko, P. E., Rivier, J., and Vale, W. W. (1983). Organization of Ovine Corticotropin-releasing factor immunoreactive cells and fibers in the rat-brain: an immunohistochemical study. Neuroendocrinology 36, 165-186. doi: $10.1159 / 000123454$

Timpl, P., Spanagel, R., Sillaber, I., Kresse, A., Reul, J. M. H. M. Stalla, G. K., et al. (1998). Impaired stress response and reduced anxiety in mice lacking a functional corticotropin-releasing hormone receptor 1. Nat. Genet. 19, 162-166. doi: 10.1038/520

Vale, W., Spiess, J., Rivier, C., and Rivier, J. (1981). Characterization of a 41-residue ovine hypothalamic peptide that stimulates secretion of corticotropin and betaendorphin. Science 213, 1394-1397. doi: $10.1126 /$ science. 6267699

Wang, X.-D., Chen, Y., Wolf, M., Wagner, K. V., Liebl, C., Scharf, S. H., et al. (2011). Forebrain CRHR1 deficiency attenuates chronic stress-induced cognitive deficits and dendritic remodeling. Neurobiol. Dis. 42, 300-310. doi: 10.1016/j.nbd.2011.01.020

Vaughan, J., Donaldson, C., Bittencourt, J., Perrin, M. H., Lewis, K., Sutton, S., et al. (1995). Urocortin, a mammalian neuropeptide related to fish urotensin $\mathrm{I}$ and to corticotropin-releasing factor. Nature 378, 287-292. doi: $10.1038 / 378287 \mathrm{a} 0$

Veenema, A. H. (2009). Early life stress, the development of aggression and neuroendocrine and neurobiological correlates: what can we learn from animal models? Front. Neuroendocrinol. 30, 497-518. doi: 10.1016/j.yfrne.2009. 03.003
Veenema, A. H., Meijer, O. C., De Kloet, E. R., Koolhaas, J. M., and Bohus, B. G. (2003). Differences in basal and stress-induced HPA regulation of wild house mice selected for high and low aggression. Horm. Behav. 43, 197-204. doi: 10.1016/S0018506X(02)00013-2

Wendelaar Bonga, S. E. (1997). The stress response in fish. Physiol. Rev. 77, 591-625.

Wigger, A., Sanchez, M. M., Mathys, K. C., Ebner, K., Frank, E., Liu, D., et al. (2004). Alterations in central neuropeptide expression, release, and receptor binding in rats bred for high anxiety: critical role of vasopressin. Neuropsychopharmacology 29, 1-14. doi: 10.1038/sj.npp.1300290

Winberg, S., Nilsson, G. E., and Olsen, K. H. (1991). Social rank and brain levels of monoamines and monoamine metabolites in Arctic charr, Salvelinus Alpinus (L). J. Comp. Physiol. A 168, 241-246.

Vita, N., Laurent, P., Lefort, S., Chalon, P., Lelias, J.-M., Kaghad, M., et al. (1993). Primary structure and functional expression of mouse pituitary and human brain corticotrophin releasing factor receptors. FEBS Lett. 335, 1-5. doi: 10.1016/0014-5793(93)80427-V

Wood, S., McFadden, K., Grigoriadis, D., Bhatnagar, S., and Valentino, R. (2012). Depressive and cardiovascular disease comorbidity in a rat model of social stress: a putative role for corticotropin-releasing factor. Psychopharmacology 222, 325-336. doi: 10.1007/s00213-012-2648-6

Wood, S. K., Walker, H. E., Valentino, R. J., and Bhatnagar, S. (2010). Individual differences in reactivity to social stress predict susceptibility and resilience to a depressive phenotype: role of corticotropinreleasing factor. Endocrinology 151, 1795-1805. doi: 10.1210/en.20091026

Woods, R., Grossman, A., Saphier, P., Kennedy, K., Ur, E., Behan,
D., et al. (1994). Association of human corticotropin-releasing hormone to its binding protein in blood may trigger clearance of the complex. J. Clin. Endocrinol. Metab. 78, 73-76. doi: 10.1210/jc. 78.1.73

Wunderink, Y. S., Engels, S., Halm, S., Yúfera, M., Martínez-Rodríguez, G., Flik, G., et al. (2011). Chronic and acute stress responses in Senegalese sole (Solea senegalensis): the involvement of cortisol, CRH and CRH-BP. Gen. Comp. Endocrinol. 171, 203-210. doi: 10.1016/j.ygcen.2011.01.010

Zhao, Y., Valdez, G. R., Fekete, E. M., Rivier, J. E., Vale, W. W., Rice, K. C., et al. (2007). Subtype-selective corticotropinreleasing factor receptor agonists exert contrasting, but not opposite, effects on anxiety-related behavior in rats. J. Pharmacol. Exp. Ther. 323, 846-854. doi: 10.1124/jpet.107.123208

Conflict of Interest Statement: The authors declare that the research was conducted in the absence of any commercial or financial relationships that could be construed as a potential conflict of interest.

Received: 08 May 2013; accepted: 19 June 2013; published online: 09 July 2013.

Citation: Backström $T$ and Winberg $S$ (2013) Central corticotropin releasing factor and social stress. Front. Neurosci. 7:117. doi: 10.3389/fnins.2013.00117

This article was submitted to Frontiers in Neuroendocrine Science, a specialty of Frontiers in Neuroscience.

Copyright (c) 2013 Backström and Winberg. This is an open-access article distributed under the terms of the Creative Commons Attribution License, which permits use, distribution and reproduction in other forums, provided the original authors and source are credited and subject to any copyright notices concerning any third-party graphics etc. 